\title{
The extraction of phrase structure during reading: Evidence from letter detection errors
}

\author{
ASHER KORLAT \\ University of Haifa, Haifa, Israel \\ and \\ SETH N. GREENBERG \\ Union College, Schenectady, New York
}

\begin{abstract}
In light of recent suggestions regarding the prominence of structure in speech production and comprehension, it has been postulated that structural processing might also play a similarly important role in reading. Some evidence in support of this contention can be gleaned from eye-movement research. However, more systematic support comes from recent work on letter detection during reading, which has shown that the rate of omission errors is inordinately high for morphemes that disclose phrase structure. The results of three lines of research suggest that, early in text processing, readers attempt to extract a structural frame for the sentence to help the on-line integration of accessed representations, and that structure-supporting units recede to the background as the meaning of the sentence evolves.
\end{abstract}

"Twas brillig, and the slithy toves did gyre and gimble in the wabe." These first two lines of Lewis Carroll's poem "Jabberwocky" leave the reader with the uncomfortable feeling of comprehending pure nonsense. Although there appears to be precious little to comprehend, an invisible structure seems to carve a rhythm and familiarity out of this gibberish. Upon close examination, though, we find hints about why the text imparts these feelings. Although the text is devoid of most words that convey meaning, it is fashioned so that it mimics the familiar structure of ordinary text. This is achieved by the strategic placement of function morphemes that convey organization and by suffixes that suggest the intended syntactic function of the nonsense words. These cues help to build a structural framework for the sentence, which constrains the syntactic role of the individual units, thereby creating the impression that one can grasp some rudimentary meaning of the sentence as a whole, without comprehending its constituent content units.

Readers who are presented with Jabberwocky-type text typically report that the text is "like English," but they find it difficult to explain why. Nevertheless, some readers are willing to guess what the text is about, and they do so in terms of a primitive, abstract schema-for

The authors made equal contributions to this research, which was supported by Grant 88-00395 from the United States-Israel Binational Science Foundation (BSF), Jerusalem, Israel. We wish to thank Hamutal Kreiner for her help in setting up the experiments and preparing the manuscript. We are grateful to Bob Crowder, Lester Krueger, and Betty Ann Levy for their helpful comments on an earlier version of the paper. Correspondence should be addressed to A. Koriat, Department of Psychology, University of Haifa, Haifa, Israel, or to S. N. Greenberg, Department of Psychology, Union College, Schenectady, NY 12308. example, "someone is doing something to someone somewhere (or at some time)." It strikes us that, in reading normal text, the elements that impart information about the abstract schema of the sentence - functor morphemes-generally receive little attention, and hence their contribution to text processing is unappreciated by the reader (see Carr, Brown, \& Charalambous, 1989). Perhaps this is because the semantically laden content words are the focus of attention in normal text. Nevertheless, we propose that, even in normal text, functors contribute to the development of the overall abstract schema for the sentence as a whole. Such a structural schema is necessary to help the reader integrate information across individual units. Thus, we embarked on a research project designed to discover how function morphemes might silently contribute to the evolving structural representation for a sentence as a whole during the on-line processing of normal text. Impetus for the project also came from the observation that the difficulty encountered by some aphasic/dyslexic patients when reading function words can be mitigated by placing these units in sentential slots, where they play more than a function role (Andreewsky, Deloche, \& Kossayni, 1987; Morton \& Patterson, 1987).

These observations regarding function units suggest the precedence of structural contributions over semantic contributions, and they led us to propose a structural account of reading. According to this account, the online analysis of text requires the encoding of both structure and meaning. However, the processing of structure leads the way to the processing of meaning, so the interpretation of individual units is constantly subordinated to the encompassing phrasal structure in which they are embedded. 


\section{STRUCTURAL PRECEDENCE IN SPEECH PRODUCTION, SPEECH COMPREHENSION, AND READING}

Before we describe supportive evidence from the study of reading, we will examine some relevant insights from speech processing that bear upon the concept of structural precedence. First, consider speech production. Examination of naturally occurring speech errors indicates that many of them involve substitution of words from the same grammatical class. This and other observations have led to "frame-and-slot" models of speech production (Bock, 1990; Dell, 1986; Garrett, 1975). According to these models, a speaker begins with an idea for which the appropriate lexical items are selected, and then these items are assigned to syntactic "functional" slots-for example, noun, verb, modifier, and so on-within independently created frames. Bock proposed that the assignment of lexical units to structure represents an integral but independent process in creating spoken output. Evidence supporting her contention comes from studies in which a sentence-priming paradigm was used, and the results indicated that syntactic structure can be activated independently of meaning (e.g., Bock \& Loebell, 1990). Thus, a passive structure initiated by a first speaker most often elicits a similar passively structured response from a second speaker. Bock (1990) concludes that "syntactic forms sometimes run free of meanings" (p. 1221).

What are the implications of these ideas for the decoding of verbal messages? It is our thesis that the processes underlying the comprehension of both spoken and written messages recapitulate the general architecture of speech production: The extraction of structure precedes and paves the way for the extraction of meaning. Essentially, both the listener and the reader strive to quickly establish a rudimentary frame-and-slot organization of the phrase or the sentence into which incoming units can be placed. Such a structural frame can help the interpretation of each individual unit in terms of its role within the entire sentence and the integration of information across the various units. Of course, unlike speech production, in which an abstract framework can be completely defined before its slots are filled in by the appropriate lexical units, in both speech comprehension and reading, the abstract framework must be reconstructed on line from the successively accessed representations. Therefore, if this framework is to guide the full semantic analysis of the phrase or the sentence, it must be extracted relatively early, on the basis of a shallow analysis, taking advantage of cues that can reveal the structure of a message before its content has been fully analyzed.

Prominent among cues that reveal syntactic structure are function units. These operate like trail markers, navigating the reader through unfolding structures. They appear in reasonably predictable locations, and they help define common syntactic frames. To illustrate, consider the following common frames: "on the one hand-on the other hand-_," or "not only_-but also-_." The open- ing words of these frames are sufficient to set a rough structure for what is about to come. These words not only sensitize the listener/reader to the anticipated structuresupporting functors (the reader is invited now to guess the next word in this sentence), but also help the on-line assimilation of the content units into an organized meaning schema. It is important to note that, although pragmatic and semantic expectations can contribute to the specification of structural frames, such frames can generally be extracted independently of meaning. Therefore, a top-down activation emanating from the quickly established primitive structures can dominate lexical access and semantic analysis in an interactive analysis-bysynthesis process (see Neisser, 1967).

A potent cue for structure that is available in speech comprehension, but not in reading, is prosody - the intonation, stress, rhythm, loudness, and rate of utterance (Gee \& Grosjean, 1983). Prosody often helps to communicate and emphasize syntactic structure. As an example, Kelly (1992) found a correlation between stress patterns and linguistic role: Stress patterns found for nouns differ from those of verbs, and the patterns found for open-class words differ from those of closed-class words. Such stress differences occur only when words are embedded in sentential context, suggesting that the specification of stress is intimately tied to the oral communication of structure (Sorenson, Cooper, \& Paccia, 1978). Thus, prosody can help the listener assign individual units to grammatical classes even before lexical access has been completed. Beyond that, though, prosodic information is often instrumental in specifying the structural relationship between words. Consequently, disambiguation of syntactically ambiguous sentences must often depend upon prosodic patterns to clarify the intended structure. However, prosody is also important when sentences contain no structural ambiguity. Thus, speech comprehension is impaired when stress patterns are eliminated or made inconsistent with structure (Carroll \& Slowiaczek, 1987). Apparently, then, the articulation of structure in one form or another is a necessary part of communication through speech, and both the speaker and listener share an implicit assumption regarding the critical role of structural cues in speech comprehension. It is our conjecture that although prosody is a useful cue for structure, like other structural cues (see below), it leaves very few long-lived memory traces after it has been utilized to aid structural extraction and comprehension.

Although prosodic cues aid the listener's extraction of structure, the reader is deprived of such cues. However, the reader can still take advantage of a variety of cues to establish the organization of text on line. Furthermore, the reader has the advantage of being able to rely on parafoveal preview in structure extraction. In fact, several observations have suggested that readers tend to silently assign a prosodic pattern to text as they read, and this, perhaps, discloses their attempt to set structure on line on the basis of some crude cues. At the most elementary level, superficial cues such as spacing and word 
length seem to contribute to early perceptual analysis, and punctuation may also provide a rough indication of structure. Rayner and McConkie (1976) monitored eye movement during reading and found that readers rarely land on the spaces between words or on punctuation marks. This suggests, perhaps, that these very rudimentary cues are utilized in parafoveal preview. O'Regan (1979) observed that short function words are frequently skipped during reading. This could simply reflect the general tendency of short words to produce shorter saccades than long words. However, Inhoff, Toploski, Vitu, and O'Regan (1993) have recently observed that the skipping of letter strings, similar in length to functors, occurs much less frequently than the skipping of the functors themselves, indicating a critical contribution of syntactic role. Consistent with the notion that the reader's oculomotor movements may be guided by syntactic considerations, Rayner, Carlson, and Frazier (1983) found that reading time per character in certain types of ambiguously structured sentences is affected initially by the preferred syntactic interpretation of a sentence. It would appear, then, that the initial structural interpretation dominates even semantic and pragmatic considerations early on, and perhaps, as with the comprehension of speech, rapid on-line identification of structure is a routine part of text processing.

\section{THE ROLE OF FUNCTORS IN TEXT PROCESSING The Dominance Shift Hypothesis}

To this point, we have suggested a prominent role for structural analysis in written and spoken comprehension. Furthermore, our brief encounter with Jabberwocky text suggested that the most important cues for structure are syntactic markers, such as articles, prepositions, conjunctions, and affixes. These function morphemes not only help to set structure, but they do so independently of meaning. The literature, though, provides a mixed view regarding the role of function morphemes in reading. On the one hand, some students of reading contend that because function words are redundant and convey little semantic information, they are skipped over during reading (Haber \& Schindler, 1981). Indeed, some of the evidence reported by Haber and Schindler appears at first blush to be consistent with that position. Others, on the other hand, argue that function words are particularly helpful in the early stages of sentence processing, because they serve to signal phrase structure (e.g., Just \& Carpenter, 1987; Kimball, 1973). For example, results from eye-movement research have suggested that when a function word appears in the parafoveal region, it can often be identified without direct fixation (Rayner, Sereno, Morris, Schmauder, \& Clifton, 1989; see also Hadley \& Healy, 1991), and thus it could presumably be used to form structure. These contrasting views seem to reflect a discrepancy between those who stress the role of syntactic structure and those who emphasize semantic content in text processing.
In our structural account of reading, we attempt to resolve this paradox by postulating a dominance shift from structure to meaning. Generally speaking, the processing of text requires coding of structure as well as coding of meaning, and these are generally carried out in parallel. However, the coding of structure is assumed to precede the coding of meaning and pave the way for it (see Aaronson \& Ferres, 1983; Bock, 1990; Forster \& Ryder, 1971; Garrett, 1980). In this manner, the reading process can be seen as recapitulating the organization that is inherent in speech production, where structure is established early, and slots within this structure are then filled by their appropriate lexical units. Functors play a crucial role at this stage, often signaling the construction of a new phrase (Kimball, 1973), and they are therefore monitored early in text processing. Once the functors have been utilized to build a structural frame, however, they are dismissed, yielding to the semantically rich content units. Thus, the apparent failure of readers to take note of function units may disclose the ultimate figure-ground organization of the sentence, in which content units assume a focal role against a structural skeleton.

\section{THE MISSING-LETTER EFFECT Perceptual Unitization or Structural Analysis?}

The structural assumption--that the interpretation of individual units is subordinate to the organizing phrasal structure in which they are embedded - is reminiscent of the central assumption of the unitization model of reading. This model addresses a different but related issue, namely, the size of the units that govern the reading of text (see Besner, 1989; Henderson, 1982). Healy and her associates (e.g., Healy, 1976, 1994; Healy \& Drewnowski, 1983) distinguish several processing levels-letters, letter strings, words, phrases-and assume that readers process a text in parallel at the various levels of analysis that are available to them. They further postulate that familiarity with a unit at a given level facilitates its processing by permitting access to higher order unitized representations (e.g., word units and phrase units). Thus, highly familiar words are encoded more easily than rare words because they activate their unitized whole-word representations. Similarly, very frequent word "frames," such as "for the __." are processed readily at the phrase level. Once a unit at a given level is identified, subjects proceed to the next segment of text without completing the processing of units at lower levels-for example, constituent letters. Therefore, it should be more difficult to detect a target letter in a familiar, "unitized" word than in a less familiar word.

Support for the unitization position comes primarily from a phenomenon referred to by Healy and her associates as the missing-letter effect. In this phenomenon, letter detection in connected text is more difficult for frequent words, such as the, and, and for, than it is for less common words (e.g., Corcoran, 1966; Healy, 1976, 1994; Healy \& Drewnowski, 1983; Healy, Oliver, \& McNamara, 1987; Proctor \& Healy, 1985). This phenome- 
non has been widely replicated, and it is perhaps one of the most robust findings in reading research. According to the unitization account, the missing-letter effect is symptomatic of the size of the effective unit underlying reading. Presumably, increased familiarity of orthographic segments allows readers to process text in terms of increasingly larger perceptual units. Therefore, familiar units tend to "conceal their letters" more than less familiar units. Furthermore, the magnitude of the missingletter effect increases with increasing reading proficiency, presumably because proficient readers can process text in terms of larger orthographic units (Cunningham, Healy, Kanengiser, Chizzick, \& Willitts, 1988; Drewnowski, 1978, 1981).

The missing-letter effect particularly attracted our attention because it has been most clearly obtained with function words, which are not only very familiar, but also play a critical role in defining phrase structure. Indeed, as we have pointed out, even a cursory inspection of Jabberwocky-type text (see, e.g., Carr et al., 1989; Epstein, 1961) indicates that the great majority of the words that are kept intact are function words. (The reader is invited to try and compose Jabberwocky-type sentences without keeping some functors intact.) Thus, the missing-letter effect is precisely what should be expected from our structural view, if this effect can be shown to derive from the syntactic role of function words in text and not solely from their familiarity. If this is indeed the case, then the study of the missing-letter effect can shed light upon the process of frame extraction that is assumed to take place in the early stages of text processing.

In our studies, we tried to disentangle the common confounding between frequency or familiarity and syntactic role, focusing on the distinction between function and content morphemes. Traditionally, function morphemes have been defined to include those morphemes that are devoid of content, but supply structural information (Aaronson \& Ferres, 1983). Among the categories of words meeting that description are prepositions, conjunctions, articles, and pronouns. However, it is recognized that words falling into these categories sometimes have functions other than standard structural roles-for example, on in "on switch." So although we continue to refer to such words as function units, we acknowledge that they may be more "content like" in certain contexts. We also assume that function words may sometimes have diminished structural roles in some contexts--for example, when a preposition trails a verb ("the book I looked for"). Hence, our specific intent in our studies was to distinguish between words and morphemes that make important contributions to the structural organization of the sentence and items that either contribute primarily to the sentence's content and/or make little contribution to its structure.

The distinction between the unitization account and the structural account of the missing-letter effect may reflect Bock and Cutting's (1992) general distinction between the serial and hierarchical models of language processing. Both accounts are concerned with the issue of the effective unit of language processing, and both view the missing-letter effect as deriving from the tendency to process text in terms of larger "units." They differ, however, in the nature of these units as well as in their processing assumptions. First, whereas in the unitization model the effective units are defined primarily in terms of such associative-statistical factors as orthographic frequency and semantic familiarity, in the structural model, these units comprise structural frames that represent the abstract schema of a phrase or a sentence. Second, underlying the unitization account is the assumption that reading proceeds unit by unit, and the missing-letter effect occurs primarily at the lexical stage, where these units contact their internal representations. In contrast, the structural account assumes a hierarchical organization with a dominance shift from structure to meaning and places the missing-letter effect at a postaccess stage, after the phrase has been parsed into its constituent morphemes, and after the function morphemes have been interpreted in their structure-supporting role.

Indeed, although the majority of the work produced by Healy and her colleagues has emphasized the perceptual component of the missing-letter effect, some of the work implicates syntactic contributions. Thus, in Drewnowski and Healy's $(1977,1980)$ studies, detection of $n$ was more difficult in the familiar letter string ing when that string represented a single morpheme (e.g., having) than when it completed the stem of a word (e.g., during or bring). Additionally, the search for the letter $n$ in the context and was unaffected by whether readers searched for and or $n$, but detecting $n$ in ing was much better when the readers searched for the ing unit than when they searched for the single target letter $n$. More recent work by Moravcsik and Healy (1993) suggests semantic contributions as well. For example, a contrastive the (e.g., "Which president? You don't mean the president?') generated fewer errors than did a normal the. These and similar findings suggest that letter detection is affected not only by orthographic familiarity but also by the syntactic and semantic role of the word.

In a recent elaboration of the unitization position, Healy (1994) acknowledges that letter detection may come under the influence of syntactic and semantic factors. Specifically, she proposes that the speed at which a word's syntactic and semantic features are accessed affects the visual processing of its constituent letters in such a way that slower syntactic/semantic identification allows the reader more opportunity to complete the finegrained visual processing of the letters. Our present experimental work lends further support to the idea that letter detection depends critically on syntactic and perhaps semantic analysis, but our interpretation of these effects differs somewhat from Healy's. According to Healy, the missing-letter effect reflects processes that occur during word identification, when visual, semantic, or syntactic familiarity affect speed of lexical access, but the structural account attributes the effect to processes that occur after word (or morpheme) identification is 
complete, when the function morpheme is exploited in forming a structural frame for the sentence.

\section{EXPERIMENTAL EVIDENCE}

We developed three research strategies to test our structural position, all of which rely on the letter detection task. In all the experiments, subjects were required to read passages at their normal speed and to circle a predesignated target letter. All three approaches yielded data that were consistent with our interpretation, as did several extensions of these initial efforts. We have conducted close to 30 experiments, but we draw attention to only a subset of that work to help make our point. These relevant data are summarized in Table 1 and described in the following text.

\section{Detection of Function Prefixes in Hebrew}

Given the apparent difficulty of disentangling function from frequency in English text, we first chose to explore the issue by using Hebrew (Koriat, Greenberg, \& Goldshmid, 1991). Hebrew provides alternate forms for several of its function morphemes. For example, the word to can appear either as the two-letter word $e l$, or as a single-letter prefix $l$ appended to word stems (e.g., "to David" may be translated as either el david or ldavid; Hebrew has no capital letters). Because both forms have nearly identical functions and meanings in the Hebrew language, two equivalent phrases can be constructed. The word $e l$ is a very short and frequent function word, much like to is in English, whereas $l$ prefixed to word stems yields an orthographic pattern that is not particularly common. In fact, it must be less frequent than the stem to which the $l$ has been attached. Note that the same target letter $(l$, in this case) appears in both forms. If the frequency of the orthographic string is the critical factor for letter omissions, then the missing-letter effect should be obtained for the frequent function word $e l$, but not for the function prefix $l$. But if the role of a morpheme is critical, the word $e l$ and the prefix $l$ should both produce more errors than the content words. Note that the content words to which the function items were compared were also short and displayed target letters in the initial position, as did the prefix words. Since both the critical content and prefix Hebrew words began with the same target letters, a difference between these two conditions would have to be attributed to the role of the initial letter within the word sequence. Moreover, because the prefix words that we used were the result of combining a content word with an added morphemic unit, these words were no more familiar than the content words to which they were compared (e.g., "to Haifa," is less frequent than the root "Haifa").

The initial study (Koriat et al., 1991, Experiment 1), conducted with proficient native readers of Hebrew, included four different functors (to, in, from, that/who). Each of these appeared either as a function word or as a function prefix in a sentence. In addition, matched sentences were used, in which the critical word was a con- tent word. The target letter was represented as the first letter of the prefix and content words and as the first (for in and from) or the second letter (for to and that/who) of the function words. As can be seen in Table 1 (Study A), letter detection was significantly poorer in function words than in content words, replicating the missing-letter effect. However, it was also poorer in function prefixes. These, in fact, engendered significantly more errors than the more familiar function words. Note that this pattern-inferior letter detection performance for the function prefixes - was obtained even for the two function morphemes in and from, for which the target letter was always represented as the initial letter of the word. Critically, then, function units are concealed because of their syntactic role-not because of their familiarity.

In a second study (Koriat et al., 1991, Experiment 3), it was demonstrated that the missing-letter effect for a Hebrew prefix word is confined to the letter representing the function morpheme and does not extend to the other letters in the word. The critical words in that study were matched prefix and content words that contained the same number of letters and represented the same letters in both the initial position and another (ultimate or penultimate) position (e.g., Ir $r$, meaning "to the Rabbi," vs. $l h b$, meaning "blade," with $l$ or $b$ as the targets). Once again, content words were matched to function prefix words so that in each case the target letters occupied the initial location in our critical words as well as a later location. As can be seen from Table 1 (Study B), for prefix words, letter detection was considerably more difficult when the target to be searched was the initial letter (prefix) than when it occupied another position (i.e., part of the stem), but the reverse was true for the unprefixed content words. This result implies that prefix words, if anything, are less unitized than their matched content words, because of the differential detectability of their constituent letters. Furthermore, the results are consistent with the dominance shift hypothesis, in that they indicate that the locus of the missing-letter effect is at a postlexical stage, after the word has been parsed into its proper constituent morphemes.

Finally, in another experiment (Koriat et al., 1991, Experiment 4), we took advantage of the Hebrew language's bounty of homographic structures. As a Semitic language, Hebrew in print is rarely vowelized, so quite often the same sequence of consonants can have two very different meanings (see Frost, Katz, \& Bentin, 1987; Koriat, 1984). Of interest for the present study are constructions for which the same consonant string (e.g., $s m r$ ) can be interpreted either as an unprefixed content word (meaning "kept"), or as a prefix word, in which the initial letter ( $s$, meaning "that") represents a function morpheme, and the trailing letters represent a content morpheme ( $m r$, meaning "mister"). The results indicated (see Table 1, Study C) that the detection of the initial letter of such ambiguous words was significantly worse when prior disambiguating context favored its interpretation as a function prefix rather than as part of a 
Table 1

\begin{tabular}{|c|c|c|c|}
\hline \multicolumn{4}{|c|}{$\begin{array}{c}\text { Summary of Mean Percentage of Omission Errors for Different Conditions } \\
\text { in Eight Studies Representing Three Experimental Approaches }\end{array}$} \\
\hline Study & Condition & Errors & Source \\
\hline \multicolumn{4}{|c|}{ Hebrew Experiments } \\
\hline A & $\begin{array}{l}\text { Function prefix } \\
\text { Function word } \\
\text { Content word }\end{array}$ & $\begin{array}{l}22.6 \\
17.5 \\
10.7\end{array}$ & Koriat et al., 1991, Experiment 1 \\
\hline B & $\begin{array}{l}\text { Prefix words } \\
\text { Initial letter } \\
\text { Other }\end{array}$ & $\begin{array}{l}23.1 \\
14.0\end{array}$ & Koriat et al., 1991, Experiment 2 \\
\hline & $\begin{array}{l}\text { Content words } \\
\text { Initial letter } \\
\text { Other }\end{array}$ & $\begin{array}{l}10.3 \\
14.5\end{array}$ & \\
\hline $\mathrm{C}$ & $\begin{array}{l}\text { Function prefix interpretation } \\
\text { Content word interpretation }\end{array}$ & $\begin{array}{l}16.7 \\
13.0\end{array}$ & Koriat et al., 1991, Experiment 4 \\
\hline \multicolumn{4}{|c|}{ Nonword Experiments } \\
\hline $\mathrm{D}$ & $\begin{array}{l}\text { fom as function word } \\
\text { fom as content word } \\
\text { fol as function word } \\
\text { fol as content word }\end{array}$ & $\begin{array}{r}36.0 \\
10.0 \\
11.5 \\
4.0\end{array}$ & Koriat \& Greenberg, 1991, Experiment 1 \\
\hline E & $\begin{array}{l}\text { Hebrew prefix nonwords } \\
\text { Hebrew content nonwords } \\
\text { Hebrew prefix words } \\
\text { Hebrew content words }\end{array}$ & $\begin{array}{r}18.1 \\
7.7 \\
15.5 \\
4.4\end{array}$ & Koriat \& Greenberg, 1991, Experiment 2 \\
\hline \multicolumn{4}{|c|}{ Functors in Different Structural Roles } \\
\hline $\mathrm{F}$ & $\begin{array}{l}\text { for in "for or against" } \\
\text { for in "for better or worse" } \\
f \text {-content words }\end{array}$ & $\begin{array}{r}25.0 \\
5.8 \\
7.1\end{array}$ & Greenberg \& Koriat, 1991, Experiment 1 \\
\hline G & $\begin{array}{l}\text { on as a preposition } \\
\text { on as a modifier } \\
n \text {-content words }\end{array}$ & $\begin{array}{l}42.0 \\
17.2 \\
17.9\end{array}$ & Greenberg \& Koriat, 1991, Experiment 2 \\
\hline $\mathrm{H}$ & $\begin{array}{l}\text { for in a critical structural role } \\
\text { for in a noncritical structural role } \\
\text { f-content words }\end{array}$ & $\begin{array}{r}27.0 \\
3.0 \\
5.0\end{array}$ & Greenberg \& Koriat, 1991, Experiment 3 \\
\hline
\end{tabular}

content word. These findings clearly argue that letter detection depends upon the function of the unit in which it appears, and they provide further support for the hypothesis that the locus of the missing-letter effect is at a postlexical, postparsing stage, in which the interpretation of individual morphemes is subordinated to the interpretation of the phrase or sentence. Thus, paradoxically, letters are missed precisely because they are found to carry structural information.

Altogether, the results of the Hebrew studies cannot be explained by a simple version of the unitization model, which proposes that letters in function words are missed because they are concealed by the unitized representation of the word as a whole. Thus, a data-driven process that responds strictly to visual familiarity cannot explain the difficulty in detecting function prefixes, because this difficulty seems to depend on the proper interpretation of the orthographic string in which they are embedded. In fact, the observation that letter detection in prefix words was inordinately difficult only for the prefix letter suggests that the missing-letter effect occurs at the level of the morpheme rather than at the level of the entire word. Furthermore, in prefix words, the target is the same size as the morpheme, and therefore the prefix disadvantage cannot be explained in terms of the tendency of larger units to hide their constituent letters. As noted earlier, however, the most recent version of the unitization account of letter detection errors (Healy, 1994) acknowledges the contribution of semantic/syntactic analysis as well as the frequency of the word in which the target is embedded.

\section{Letter Detection in Nonwords}

A second approach, inspired in part by the Jabberwocky poem, was to have readers detect letters in largely coherent text that included, on occasion, nonsense letter strings (Koriat \& Greenberg, 1991). Importantly, the location of these nonsense strings was systematically manipulated so that they appeared in slots that would normally require function words (or morphemes), or in those normally occupied by content words. Because the critical items were nonsense strings, it was sometimes possible to hold orthography of the target strings constant across function and content slots. These experiments were conducted in both English and Hebrew, so we could assess whether the support for the structural position would also hold for English text.

The results from one experiment (Koriat \& Greenberg, 1991, Experiment 1; see Table 1, Study D) showed that short English nonsense strings ( fol or fom) engen- 
dered nearly three times as many errors when they appeared in a function location (replacing for; e.g., "The captain called fol his crew") than when they appeared in a content location (e.g., replacing fog; e.g., "The ship was lost in a fol"). Although this effect was significant for both fom and fol, supporting the notion that function is critical, the fact that more errors were made on fom than on $f o l$ suggests that visual appearance may also be a factor, because fom is more visually similar to for than is fol. Balota, Pollatsek, and Rayner (1985) have also demonstrated that, for somewhat predictable text, visual factors may be important in assessing a word in the parafovea (also see Hadley \& Healy, 1991).

Even more impressive results were obtained in an experiment that focused on Hebrew function prefixes that were attached to word or nonword stems (Koriat \& Greenberg, 1991, Experiment 2). The advantage of this design is that a nonword (e.g., lgnr) can be used in a slot where the initial letter is likely to be interpreted as a function prefix ("to $g n r$," $g n r$ being a nonword) and in a slot where it is likely to be interpreted as part of the stem of a content word (e.g., "He went lgnr" vs. "He ate lgnr"). Detection errors for the initial letter of these nonword conditions were compared with those for prefix words and content words. As can be seen in Table 1 (Study E), the results were clear cut: The magnitude of the functiondisadvantage effect was practically identical for words and nonwords!

Overall, the results with nonwords clearly demonstrate that the missing-letter effect can be obtained even for letter strings with zero frequency of occurrence in the language. This effect is tied to the syntactic structure of the sentence, and it occurs even with strings that are devoid of semantic content.

\section{Function Words Assuming Different Structural Roles}

Our third approach was to show that the rate of detection errors for the same exact "functor" differs, depending on its specific role within the sentence (Greenberg \& Koriat, 1991). In one experiment (Greenberg \& Koriat, 1991, Experiment 1), the expression for or against was contrasted with the similarly familiar phrase for better or worse. In the former expression for's role is more like that of a noun, but in the latter expression its role is that of the traditional preposition. As Table 1 (Study F) shows, letter detection was much worse when for contributed to structure than when it did not. In fact, detecting $f$ in for or against was no more difficult than detecting $f$ in content words.

Similar results were obtained in a second experiment (Greenberg \& Koriat, 1991, Experiment 2), in which the detection of $n$ in the target word on was examined. This word appeared either in a structure-supporting prepositional capacity (e.g., on his way) or in the role of a modifier (e.g., on switch). Prepositional use of on produced significantly more errors than the use of on as a modifier (see Table 1, Study G).
Interestingly, these results persisted, even when the context preceding the critical preposition was held constant (e.g., searching for $f$ in "Everybody wants to know whether you are for abortion" vs. "Everybody wants to know whether you are for or against"). Thus, it was not until the subjects had passed the target word (for) that its role in the sentence was reasonably clear. Nevertheless, as can be seen from Table 1, Study H (Greenberg \& Koriat, 1991, Experiment 3), the error rate for a preposition as a functor was considerably higher than that for a preposition not playing a critical structural role.

Together, then, all three lines of research converge to support the structural model. The Hebrew studies suggest that letter detection errors in function morphemes occur after these morphemes are identified and interpreted as carriers of structural information. The nonword studies indicate that the function-disadvantage effect can be found with unfamiliar letter strings when these (or parts thereof) are seen to stand for a function morpheme. Finally, the results of the studies in which function words were used in a nontypical role clearly help tie the missing-letter effect to the syntactic role of the "functor" within the sentence. Thus, letter detection is difficult in certain morphemes precisely when these morphemes are found to convey structural information. Presumably, functors are initially identified and utilized to establish a structural frame for the sentence. Once they have been exploited to define the frame of the sentence, they recede to the background as the meaning of the sentence evolves. It is the suppression of function units in the evolving representation of the sentence that makes it difficult to detect their constituent letters.

\section{HOW STRUCTURAL FRAMES ARE ESTABLISHED}

Although we do not yet have a complete grasp of the process by which structural frames are established during reading, several results have suggested that the extraction of tentative frames is determined by a collaborative interaction between syntactic, semantic, lexical, and visual factors (see Koriat \& Greenberg, 1991, 1993). First, readers presumably monitor text for function units and attempt to use them as anchors around which to build tentative phrase-level frames. Thus, even with Jabberwocky-type or scrambled sentences, proficient readers tend to utilize such units as kernels around which to build rudimentary local structures. A short exercise in reading text with randomly placed functors is convincing evidence that it is difficult not to begin to build structures around them. This is possibly why letter detection in function units remains difficult, even when these units are misplaced in text.

Second, syntactic/semantic constraints also guide the establishment of structural frames. Therefore, letter detection in English function words improves when word order is scrambled (Drewnowski \& Healy, 1977; Healy. 1976). Thus, in our studies, when function words were 
moved to content slots in a sentence, detection errors were dramatically reduced for both Hebrew and English (Koriat \& Greenberg, 1991). Importantly, though, the placement of content words in function slots did not increase detection errors, which is consistent with the idea that the function units are specifically monitored during reading. Presumably, then, sentential context helps guide the extraction of structure by generating expectancies regarding the sentential slots where function words are likely to reside. Contextual constraints also help in parsing Hebrew nonword strings into their "function" plus "content" constituent morphemes, generating more detection errors for the function component.

Finally, visual factors also play a role. This is probably because frame extraction is based on a fast-moving process that can make do with a shallow perceptual analysis. Thus, nonwords that bear a strong visual similarity to the expected function words might serve to cue a tentative frame. It may be that parafoveal preview, which does not afford a high resolution, is sufficient to support the kind of structural frames that are responsible for the function-disadvantage effect. Indeed, eye-movement studies have suggested that when a reader fixates a content word that is followed by a short function word, the function word can be identified without a direct fixation (see Rayner \& Pollatsek, 1989; Rayner et a1., 1989).

\section{FURTHER EXTENSIONS}

We conclude our review of the empirical evidence with a brief discussion of some recent research, which has helped us to refine and expand our position.

\section{Processing Multifunctor Sequences}

In the present work, we evaluated single-functor morphemes in phrases in which they were surrounded by content units. However, in text, it is common that several functors will appear grouped together. What is the role of each morpheme in a functor sequence? According to the unitization position, function word sequences may be processed in terms of unitized two-word or three-word frames (e.g., on the ___; see Drewnowski \& Healy, 1977). Indeed, the, for example, often appears in the context of familiar word sequences such as on the or for the, which are among the most frequent two-word sequences in English (Umeda \& Kahn, 1982). Presumably, if such frames are processed as unitized orthographic patterns, this should make letter detection in their constituent frequent function words even more difficult (Healy, Conboy, \& Drewnowski, 1987).

According to the structural position, in contrast, local context contributes to the missing-letter effect by facilitating the extraction of phrase structure. Thus, in one study (Greenberg, Koriat, \& Shapiro, 1992), we used the frequent two-word sequence for the and showed that structural organization overrides perceptual organization (i.e., the presumed unitization of the familiar twoword sequence) in affecting letter detection. Specifi- cally, we compared sentences in which for and the were part of the same syntactic grouping (e.g., "He was looking for the book in his room"), with those in which they belonged to different phrases (e.g., "The book he was looking for the night of the party"). Presumably, in the latter case, for is a dangling preposition at the end of a phrase, and therefore its structural contribution is small. Indeed, the detection of $t$ in the remained equally difficult across the two contexts, but the detection of $f$ was much improved when it was at the end of the phrase. Thus, letter detection errors in a familiar sequence of words reflect their structural organization rather than their perceptual familiarity.

The lack of uniformity in the missing-letter effect across several consecutive functors is detailed further in Koriat and Greenberg (1993). Multifunctor sequences in Hebrew can consist of several one-letter prefixes strung together. They are then attached to a word stem to form a complex single-word unit (e.g., vmhgn, meaning "and from the garden," with gn standing for "garden," and the prefixes $v, m$, and $h$ standing for "and," "from," and "the," respectively). When such Hebrew function prefixes were used, only the initial prefix of a multifunctor sequence was found to yield more errors than comparable letters in similar positions in nonprefixed content words. In another study in which Hebrew function words (rather than function prefixes) were used, the error rate was high for all functors in a sequence, but here too it was highest for the leading functor. A similar pattern was found for multifunctor sequences in English (e.g., and from). These results are consistent with the proposal that the extraction of structural frames is based on a fast, on-line, shallow analysis of text that utilizes parafoveal preview (see Hadley \& Healy, 1991; Koriat \& Greenberg, 1991). Presumably, when a phrase contains a series of functors, the first of these is automatically used as a place holder, and it comes to play a dominant role in marking syntactic structure. Interestingly though, unlike the other functors used in the English study, the yielded an inordinately high rate of errors, whether it was the only functor (e.g., "He took the ball"), the second functor (e.g., "He went to the market"), or the third functor (e.g., "And in the house they found..."), perhaps because it carries more reliable structural information about the sequence of words that follow.

These results suggest that the letter detection task is sensitive to subtle differences in the contribution of different units to the evolving structural frame. They also concur with previous findings indicating that letter detection for the same orthographic pattern can vary, depending on its morphemic function. Thus, Abramovici (1983) noted that subjects were more accurate in locating misspellings in was when it had a primary function (e.g., "He was big") than when it had an auxiliary function (e.g., "He was coming"). Also, using French, Marie Poirier recently found significantly more omission errors in les when it stood for the definite article than when it stood for "them" (personal communication, June 8, 1993). 


\section{Developmental Trends in Letter Detection}

Another direction that our research has taken concerns developmental changes in the sensitivity to sentential structure (Greenberg, Koriat, Glastetter, \& Vellutino, 1994). Our structural model leads us to expect that the magnitude of the missing-letter effect for function words should increase with reading proficiency, due to the increased sensitivity to sentential structure. Such an increase has already been reported, but it has been attributed to the increased tendency to utilize wholeword, unitized representations in reading familiar words (Cunningham et al., 1988; Drewnowski, 1978, 1981). Recently, however, we found this increase to hold even when the critical function and content words were equated for frequency of occurrence (Greenberg et al., 1994). This contrast between words of relatively equal familiarity is at odds with the word-familiarity unitization position. It would seem, then, that the developmental changes in letter detection patterns are symptomatic of the increasing role played by structure during text analysis. In fact, adult readers made more errors in function words than did children, presumably because of their greater reliance on function units in establishing phrase structure.

These results, perhaps, can help link the unitization and structural hypotheses while also clarifying their distinctive emphases. It is possible that proficient readers are better able to extract structures that integrate information across a larger number of reading units than are beginning readers. In this sense, it may be said that they process text in terms of "larger units." These units, however, consist of syntactically organized patterns rather than simply familiar orthographic templates. One of the components of reading proficiency, then, involves the ability to extract the structure underlying a phrase or a sentence and to utilize it in guiding the on-line integration of individual units into an overall meaning schema.

\section{THE DOMINANCE SHIFT FROM STRUCTURE TO MEANING Some Possible Mechanisms}

Before summarizing our thesis, we wish to offer some speculative remarks regarding the mechanisms underlying the transition from structure to meaning. The impetus for the structural view of reading that has been articulated in this paper derived from the paradoxical pattern of observations that suggested that letters are difficult to detect in function morphemes precisely because of the structural role played by these morphemes in the sentence. A further suggestion is that this effect is obtained even when that role cannot be specified on the basis of such superficial features as orthographic familiarity. This pattern of results is analogous to the observation that suggests that the difficulty that some aphasic/ dyslexic patients have when reading function words is tied specifically to the syntactic role of these words within the sentence (Andreewsky et al., 1987; Morton \& Patterson, 1987). It appears, then, that functors are lost after-not before-they have been properly interpreted. We therefore proposed that the missing-letter effect reflects the diminished perceptual status of functors after they have been utilized to form an organizational scheme within which semantic analyses are conducted.

Granted, function morphemes are critical for establishing structural frames at a relatively early stage in text processing, but why are their constituent letters missed more often than those of content words? Although we have no definite answer at present, we can point to some theoretical discussions that could provide us with a lead to an answer.

One possibility is that the processing of structural information requires little attention, and once a structural frame has been established, it becomes transparent; the semantic content of the sentence is coded through it. This idea of structural transparency can be conveyed best in terms of Jacoby and Kelley's (1987) distinction between tool and object, which was borrowed from Polanyi (1958). Polanyi noted that, after reading his morning correspondence, if he wished to pass a letter on to someone who read only English, he often had to go back to the letter to determine the language in which it was written. Thus, the language of the text is often treated as a tool for conveying meaning (object), and it therefore goes unnoticed. In order to specify the language of the text, the language itself must be made the object of attention.

In applying this distinction to memory, Jacoby and Kelley (1987) noted that memory for a previous event can be used either as a tool or as the object of attention. Importantly, even when memory is used as a tool, it can have pervasive unconscious effects on performance, and these effects can be escaped only by making the prior event the object of attention.

Perhaps in reading for comprehension, the structure of a sentence, like its language, is treated only as a vehicle for accessing meaning. Although it provides a useful organizational framework that helps to integrate information across different units, it remains largely transparent, and it is processed and utilized with little attention. Perhaps also, as in the memory phenomena discussed by Jacoby and Kelley (1987), structural information exerts its pervasive effects on sentence processing precisely because of its tool-like, transparent nature.

According to this formulation, it may not be necessary to postulate a shift in attention from structure to meaning: Although the processing of structure may precede and lead the way to the processing of meaning, it can be carried out with little attention from the start. However, note that, as our results suggest, a great deal of processing must still take place for the structural frame of a sentence to be established.

Alternatively, we may propose that structure-supporting units recede to the background only after they have been exploited in defining the overall structure of the phrase. That is, the missing-letter effect is symptomatic of the utilization of function units in defining a structural frame. This idea is similar to that advanced in the context of 
person perception. For example, Rommetveit (1960) addressed the common observation that people can form clear impressions of others without being able to spell out the reasons for these impressions. He proposed that this sort of discrimination without awareness occurs because perceivers tend to utilize a variety of "proximal" cues to make judgments about a "distal" personality trait, and they tend to dispose of these cues once the judgment has been formed. Therefore, he expected that memory for the cues would be weaker when the importance of the judged trait for the perceiver was stronger. He observed, for example, that subjects who focused more heavily on "intelligence" in the perception of others were less likely to recall cues pertinent to intelligence than were those for whom intelligence was less critical. Similarly, increasing the salience of the judged attribute reduced memory for the cues pertinent to that attribute. Presumably, then, "proximal" cues tend to disappear from consciousness once they have been utilized in forming impressions about "distal" traits. Perhaps, similarly, structural cues in text tend to be dismissed once they have served to define the overall structure of the text.

Finally, the shift from structure to meaning could also be conceptualized in terms of mismatch theory, as articulated recently by Johnston and Hawley (1994). This theory was designed to resolve the apparent inconsistency between phenomena suggesting that the cognitive system is biased toward the expected and the familiar and those suggesting that it is biased toward the unexpected. According to the theory, when a familiar environment is encountered, an initial bottom-up processing triggers the appropriate conceptually driven processing, which allows the perceiver to capitalize on previous experience. This, in turn, results in the inhibition of the data-driven processing of expected inputs, accompanied by the accentuation of the data-driven processing of any unexpected input. Johnston and Hawley review a variety of phenomena supporting the notion of perceptual inhibition of expected inputs; among these is the missingletter effect. In particular, the finding that the missingletter effect is reduced by procedures that disrupt normal reading (e.g., the insertion of blanks; see Hadley \& Healy, 1991 ) is seen to support the contention that perceptual inhibition is contingent on conceptually driven processing.

Mismatch theory can account for the postulated shift from structure to meaning if the coding of structure is assumed to rely on a fast, conceptually driven processing that takes advantage of familiar words, common syntactic patterns, and contextual constraints. The Jabberwocky text illustrates how little information is needed to form a crude structure for a sentence. Once the structure of a sentence has been established, attention can then focus on the more demanding task of representing and comprehending the meaning units. One advantage of this account is that it helps accommodate the idea that the missing-letter effect is tied to semantic and syntactic familiarity (see Healy, 1994). Another advantage is that it is consistent with our recent unpublished observation-- that the missing-letter effect for a function mor- pheme is accompanied by an enhancement of letter detection in the content word that follows. We interpret this observation as support for the eventual figure-ground organization of the sentence, in which structural units recede to the background while content units are brought to the fore.

\section{OVERVIEW}

Neisser (1967) applied the idea of "analysis-bysynthesis" to reading and suggested a constructive process by which "a few words tentatively identified by the preliminary system may guide the synthesis of whole constituents as units, or even whole sentences" (p. 196). There is current experimental evidence that suggests an early stage of structural analysis in both spoken and written communication that helps to guide full semantic analysis. Indeed, it may be said that listening and reading recapitulate the rudimentary architecture of the processes underlying the construction of utterances to be spoken (or written). Evidently, speech production can follow a more tightly organized sequence, because the idea to be communicated precedes its implementation in speech. Thus, an abstract framework can be defined before its slots are filled in by appropriate lexical units. The recipient of a message, on the other hand, must recover the abstract framework from the successively accessed representations. However, if this frame is to guide the on-line semantic analysis, then it must be extracted through a "quick and dirty" process (to borrow from Enns \& Rensink, 1991), which uses a variety of structural cues to establish tentative frames. In reading, this building process apparently relies heavily on rapid detection of function units, utilizing parafoveal preview.

We argue that structural cues, as communicated by the pauses and stresses of speech, or by the punctuation and positioning of functors in printed text, grab our attention early and quickly, and lay the pathway for the semantic analysis that follows. However, although such elements are crucial to the progress of the process, ultimately a shift occurs, in which analysis of structure yields to that of meaning. In reading, this dominance shift from structure to meaning results in the paradoxical observation that function morphemes are "missed" precisely because of their importance in specifying sentential structure.

The Jabberwocky poem conveys some insight into the internal representation of a sentence after a structural framework has been established. The structure of the poem is reflected in the rhythmic pattern of intonation used by readers when reading the poem aloud, and, perhaps, the prosodic pattern in general is indicative of the structural frame established by readers (see Carroll \& Slowiaczek, 1987). The Jabberwocky poem, then, pays homage to the centrality of structural elements in guiding semantic analysis. It illustrates how the semantically impoverished functors still guide semantic analysis by imparting a structure that constrains the interpretation of units framed by them. Thus, the coding of structure can precede the coding of meaning and can be per- 
formed independently of semantic analysis. Of course, the processing of normal text proceeds beyond a Jabberwocky level, and as the meaning of the sentence evolves, the semantically rich content units gain dominance over the structure-supporting function units in the final figureground organization of the sentence.

\section{REFERENCES}

Aaronson, D., \& Ferres, S. (1983). Lexical categories and reading tasks. Journal of Experimental Psychology: Human Perception \& Performance, 9, 675-699.

Abramovici, S. (1983). Errors in proofreading: Evidence for syntactic control of letter processing? Memory \& Cognition, 11, 258261.

Andreewsky, E., Deloche, G., \& Kossanyi, P. (1987). Analogies between speed-reading and deep dyslexia: Towards a procedural understanding of reading. In M. Coltheart, K. Patterson, \& J. C. Marshall (Eds.), Deep dyslexia (pp. 307-325). London: Routledge \& Kegan Paul.

Balota, D. A., Pollatsek, A., \& Rayner, K. (1985). The interaction of contextual constraints and parafoveal visual information. Cognitive Psychology, 17, 364-390.

BESNER, D. (1989). On the role of outline shape and word-specific visual pattern in the identification of function words: NONE. Quarterly Journal of Experimental Psychology, 41 A, 91-105.

Bock, K. (1990). Structure in language: Creating form in talk. American Psychologist, 45, 1221-1236.

Bock, K., \& CutTING, C. (1992). Regulating mental energy: Performance units in language production. Journal of Memory \& Language, 31, 99-127.

Bock, K., \& Loebell, H. (1990). Framing sentences. Cognition, 35, $1-39$.

Carr, T. H., Brown, J. S., \& Charalambous, A. (1989). Repetition and reading: Perceptual encoding mechanisms are very abstract but not very interactive. Journal of Experimental Psychology: Learning, Memory, \& Cognition, 15, 763-778.

CARROLL, L. (1900). Alice's adventures in wonderland and through the looking glass. New York: Grosset \& Dunlap.

Carroll, P. J., \& SlowiaczeK, M. L. (1987). Modes and modules: Multiple pathways to the language processor. In J. L. Garfield (Ed.), Modularity in knowledge representation and natural-language understanding (pp. 221-247). Cambridge, MA: MIT Press.

Corcoran, D. W. J. (1966). An acoustic factor in letter cancellation. Nature, 210, 658 .

Cunningham, T. F., Healy, A. F., Kanengiser, N., Chizzick, L., \& WiLLITTS, R. L. (1988). Investigating the boundaries of reading units across ages and reading levels. Journal of Experimental Child Psychology, 45, 175-208.

DELL, G. S. (1986). A spreading-activation theory of retrieval in sentence production. Psychological Review, 93, 283-321.

Drewnowski, A. (1978). Detection errors on the word the: Evidence for the acquisition of reading levels. Memory \& Cognition, 6, 403-409.

DREWNOWSKI, A. (1981). Missing -ing in reading: Developmental changes in reading units. Journal of Experimental Child Psychology, 31, 154-168.

DREWNowsKi, A., \& HeALY, A. F. (1977). Detection errors on the and and: Evidence for reading units larger than the word. Memory \& Cognition, 5, 636-647.

DrewnOWSKI, A., \& Healy, A. F. (1980). Missing -ing in reading: Letter detection errors on word endings. Journal of Verbal Learning \& Verbal Behavior, 19, 247-262.

EnNs, J. T., \& Rensink, R. A. (1991). Preattentive recovery of threedimensional orientation from line drawings. Psychological Review, 98, 335-351.

EPSTEIN, W. (1961). The influence of syntactical structure on learning American Journal of Psychology, 74, 80-85.

Forster, K. I., \& Ryder, L. A. (1971). Perceiving the structure and meaning of sentences. Journal of Verbal Learning \& Verbal Behavior, 10, 285-296.
Frost, R., Katz, L., \& Bentin, S. (1987). Strategies for visual word recognition and orthographical depth: A multilingual comparison Journal of Experimental Psychology: Human Perception \& Performance, 13, 104-115.

GARRETT, M. F. (1975). The analysis of sentence production. In G. Bower (Ed.), The psychology of learning and motivation (Vol. 9, pp. 133177). New York: Academic Press.

GarReTt, M. F. (1980). Levels of processing in sentence production. In B. Butterworth (Ed.), Language production (Vol. 1, pp. 177-220). London: Academic Press.

Gee, J. P., \& Grosjean, F. (1983). Performance structures: A psycholinguistic and linguistic appraisal. Cognitive Psychology, 15, 4 II458.

GreEnBerg, S. N., \& Koriat, A. (1991). The missing-letter effect for common function words depends on their linguistic function in the phrase. Journal of Experimental Psychology: Learning, Memory; \& Cognition, 17, 1051-1061.

Greenberg, S. N., Koriat, A., Glastetter, K., \& Vellutino, F. R. (1994). Age changes in the missing-letter effect: Evidence of increased reliance on structural extraction in older readers. Manuscript submitted for publication.

Greenberg, S. N., Koriat, A., \& Shapiro, A. (1992). The effects of syntactic structure on letter detection in adjacent function words. Memory \& Cognition, 20, 663-670.

Haber, R. N., \& SChindeER, R. M. (1981). Error in proofreading: Evidence of syntactic control of letter processing? Journal of Experi. mental Psychology: Human Perception \& Performance, 7, 573-579.

HADLEY, J. A., \& HEALY, A. F. (1991). When are reading units larger than the letter? Refinement of the unitization reading model. Journal of Experimental Psychology: Learning, Memory, \& Cognition, 17, 1062-1073.

HEALY, A. F. (1976). Detection errors on the word the: Evidence for reading units larger than letters. Journal of Experimental Psychology: Human Perception \& Performance, 2, 235-242.

Healy, A. F. (1994). Letter detection: A window to unitization and other cognitive processes in reading text. Psychonomic Bulletin \& Review, 1, 333-344.

Healy, A. F., Conboy, G. L., \& DrewnowsKi, A. (1987). Characterizing the processing units of reading: Effects of intra- and interword spaces in a letter detection task. In B. K. Britton \& S. M. Glynn (Eds.), Executive control processes in reading (pp. 279-296). Hillsdale, NJ: Erlbaum.

HeALY, A. F., \& DREWNOWSKI, A. (1983). Investigating the boundaries of reading units: Letter detection in misspelled words. Journal of Experimental Psychology: Human Perception \& Performance, 9, 413-426.

Healy, A. F., Oliver, W. L., \& McNamara, T. P. (1987). Detecting letters in continuous text: Effects of display size. Journal of Experimental Psychology: Human Perception \& Performance, 13, 279-290.

HENDERSON, L. (1982). Orthography and word recognition in reading. London: Academic Press.

INHOFF, A. W., TOPOLSki, R., Vitu, F., \& O'REgAN, J. K. (1993). Attention demands during reading and the occurrence of brief (express) fixations. Manuscript submitted for publication.

JACOBY, L. L., \& KELLEY, C. M. (1987). Unconscious influences of memory for a prior event. Personality \& Social Psychology Bulletin, 13, 314-336.

Johnston, W. A., \& Hawley, K. J. (1994). Perceptual inhibition of expected inputs: The key that opens closed minds. Psychonomic Butletin \& Review, 1, 56-72.

JUST, M. A., \& CARPENTER, P. A. (1987). The psychology of reading and language comprehension. Boston: Allyn \& Bacon.

KelLy, M. H. (1992). Using sound to solve syntactic problems: The role of phonology in grammatical category assignments. Psychological Review, 99, 349-364.

Kimball, J. (1973). Seven principles of surface structure parsing in natural language. Cognition, 2, 15-47.

KorIAT, A. (1984). Reading without vowels: Lexical access in Hebrew. In H. Bouma \& D. G. Bouwhuis (Eds.), Attention and performance X: Control of language processes (pp. 227-242). Hillsdale, NJ: Erlbaum.

KORIAT, A., \& GREENBERG, S. N. (1991). Syntactic cont rol of letter detection: Evidence from English and Hebrew nonwords. Journal of 
Experimental Psychology: Learning, Memory, \& Cognition, 17, 1035-1050.

Koriat, A., \& Greenberg, S. N. (1993). Prominence of leading functors in function morpheme sequences as evidenced by letter detection. Journal of Experimental Psychology: Learning, Memory, \& Cognition, 19, 34-50.

Koriat, A., Greenberg, S. N., \& Goldshmid, Y. (1991). The missingletter effect in Hebrew: Word frequency or word function? Journal of Experimental Psychology: Learning. Memory, \& Cognition, 17, 66-80.

Moravcsik, J. E, \& Healy, A. F. (1993, November). The effect of meaning on letter detection. Paper presented at the meeting of the Psychonomic Society, Washington, DC.

Morton, J., \& Patterson, K. (1987). "Little words-No!" In M. Coltheart, K. Patterson, \& J. C. Marshall (Eds.), Deep dyslexia (pp. 270-285). London: Routledge \& Kegan Paul.

NEISSER, U. (1967). Cognitive psychology. New York: AppletonCentury-Crofts.

O'REGAN, J. K. (1979). Saccade size control in reading: Evidence for the linguistic control hypothesis. Perception \& Psychophysics, 25, 501-509.

POLANYI, M. (1958). Personal knowledge: Towards a post-critical philosophy. Chicago: University of Chicago Press.

Proctor, J. D., \& Healy, A. F. (1985). A secondary-task analysis of a word familiarity effect. Journal of Experimental Psychology: Human Perception \& Performance, 11, 286-303.

Rayner, K., Carlson, M., \& Frazier, L. (1983). The interaction of syntax and semantics during sentence processing: Eye movements in the analysis of semantically biased sentences. Journal of Verbal Learning \& Verbal Behavior, 22, 358-374.

RaYNER, K., \& MCCONKIE, G. W. (1976). What guides a reader's eye movements? Vision Research, 16, 829-837.

Rayner, K., \& Pollatsek, A. (1989). The psychology of reading. Englewood Cliffs, NJ: Prentice-Hall.

Rayner, K., Sereno, S. C., Morris, R. K., Schmauder, A. R., \& Clifton, C. (1989). Eye movements and on-line language comprehension processes. Language \& Cognitive Processes, 4, 21-49.

RoMmeTVEIT, R. (1960). Selectivity, intuition and halo effects in social perception. Oslo: Oslo University Press.

Sorenson, J. M., Cooper, W. E., \& Paccia, J. M. (1978). Speech timing of grammatical categories. Cognition, 6, 135-153.

UMEDA, N., \& KAHN, D. (1982). Frequency of occurrence of two- and three-word sequences in English. Journal of the Acoustical Society of America, 72, 2031-2033.

(Manuscript received February 9, 1994; revision accepted for publication May 16,1994 .) 